\title{
Luteinizing hormone elevation in ovarian granulosa cell tumor: a case report and review of the literature
}

\author{
Shengyuan Ran, Qi Yu*, Shan Deng and Ling Xu
}

\begin{abstract}
Background: Ovarian granulosa cell tumors (GCTs) are the most common type of potentially malignant ovarian sex cord-stromal tumor. GCTs often produce estrogen and/or progesterone; consequently, symptoms related to hyperestrogenism are common at diagnosis. Nonspecific symptoms or signs associated with this neoplasm include amenorrhea and changes in various sex hormone levels, which can be hard to diagnose or explain. The aims of this report were to describe a case of GCT with rare presentations and to review the pertinent literature.

Case presentation: A 33-year-old woman presented with secondary amenorrhea and elevated LH with normal FSH and low estradiol levels. Laparoscopy revealed an ovarian GCT, and the patient underwent left adnexectomy and platinum-based chemotherapy. Removal of the ovarian GCT resulted in the normalization of LH levels and a return to spontaneous menses.

Conclusions: The mechanisms responsible for elevations in serum LH due to GCTs require further investigation. However, addressing the patient's clinical problems remains the most important treatment consideration.
\end{abstract}

Keywords: LH elevation, GCTs, Amenorrhea

\section{Background}

GCTs are the most common type of potentially malignant ovarian sex cord-stromal tumor and comprise to $5 \%$ of all ovarian malignancies [1]. GCTs are functional tumors derived from the mesenchymal stroma of the gonad and typically presents with the elevation of sex steroids, primarily hyperoestrogenism [2]. Occasionally, other hormone changes may also be observed. Here, we report a case of histologically confirmed GCT that presented with secondary amenorrhea and elevation of only LH levels, with normal FSH and low estradiol levels and review the pertinent literature.

\section{Case presentation}

A 33-year-old Chinese woman with a 2-year history of secondary amenorrhea was referred to the reproductive endocrinology clinic at Peking Union Medical College Hospital. The patient had experienced menarche at age

\footnotetext{
* Correspondence: yuqimd@163.com

Chinese Academy of Medical Sciences and Peking Union Medical College Hospital, Beijing, People's Republic of China

12, and her menstrual cycle had been regular until 5 years ago. At that time, the patient's cycle length became irregular, with a range of 2 to 3 months. The patient did not present to the reproductive endocrinologist until her menstrual bleeding had completely stopped for 5 months.

The patient complained of hot flushes, night sweats and a $10-\mathrm{kg}$ weight gain over the last 2 years (body mass index from 17 to $20.5 \mathrm{~kg} / \mathrm{m} 2$ ). She had no clinical manifestations of hirsutism or acne. The patient's breasts and pubic hair were well- developed (Tanner stage 5) with no galactorrhea. Abdominal examination failed to reveal any palpable masses. No family history of autoimmune disorders was reported.

Serum hormone assays revealed a negative serum human chorionic gonadotropin (hCG) and a high LH level of $30.12 \mathrm{IU} / \mathrm{L}$. The other hormone levels were as follows: FSH, $7.49 \mathrm{IU} / \mathrm{L}$; estradiol, $18.2 \mathrm{pg} / \mathrm{ml}$; progesterone, $0.64 \mathrm{ng} / \mathrm{ml}$; testosterone, $0.56 \mathrm{ng} / \mathrm{dl}$; and prolactin, $7.12 \mathrm{ng} / \mathrm{ml}$, with normal thyroid function. Routine laboratory tests and tumor markers were all within normal limits. 
Pelvic ultrasonography examination demonstrated a $2.3 \times 2.0-\mathrm{cm}$ partial solid mass surrounded with a blood flow signal in the left ovary. The uterus was normal in size with an endometrial thickness of $0.3 \mathrm{~cm}$. The right ovary was unremarkable. No free fluid or other pelvic masses were observed. Magnetic resonance imaging (MRI) revealed a $5.9 \times 5.6-\mathrm{mm}$ hypoenhancing mass in the pituitary gland.

The patient had received many treatment modalities during the 2-year period at other hospitals. LH levels on the second day of oral contraceptive (ethinyl estradiol and cyproterone acetate tablets) withdraw bleeding fell to $8.51 \mathrm{IU} / \mathrm{L}$. The patient then presented to our department for further examination. Withdrawal bleeding could occasionally be induced by dydrogesterone $(10 \mathrm{mg}$ per day for 10 days per month), but this effect was inconsistent. The LH levels detected during this period fluctuated between 30 and $47 \mathrm{IU} / \mathrm{L}$. Because she failed to maintain a normal menstrual cycle in the absence of medication (she only had two episodes of spontaneous menstruation during the entire treatment period), the patient was prescribed the sequential use of estrogen and progestin to maintain regular menstruation. The high LH level (34-42 IU/L) persisted throughout the treatment course. The patient was again advised to take oral contraceptives to observe the change in LH levels. The patient developed menstrual bleeding after taking pills, and the LH level on the second day of her menstruation decreased to $7.51 \mathrm{IU} / \mathrm{L}$.

In general, the pattern of elevated LH (15.0147.85 IU/L) persisted through the 2- year period with the exception of the period of oral contraceptive use. Repeated ultrasonography examinations during her treatment period revealed that the mass had gradually grown to a solid-appearing structure measuring $2.7 \times$ $2.9 \times 2.0 \mathrm{~cm}$ in size with a rich blood flow signal. An exploratory laparoscopy was performed. The solid ovarian tumor exhibited a yellow lipid-like appearance and was $3 \mathrm{~cm}$ in diameter with rich blood flow. There was no evidence of extra-ovarian disease. A rapid frozen pathology examination of the resected tumor indicated a sex cord-stromal tumor with low malignant potential. Because the parents of this patient refused to consent to a left salpingo-oophorectomy, left cystectomy was performed. The tumor was diagnosed as an adult-type GCT with active growth on the final pathological examination, with 10 to 12 mitotic figures per 10 high-power fields (Fig. 1). The cells stained immunopositive for inhibin A, Melan-A and CD99 but were immunonegative for LH. Two weeks after the surgery, the hormone levels were as follows: LH, $13.65 \mathrm{IU} / \mathrm{L}$, and FSH, $4.9 \mathrm{IU} / \mathrm{L}$.

Unilateral adnexectomy with preservation of the contralateral ovary and the uterus is now considered adequate surgical treatment for patients with GCTs. Younger patient age and early-stage of the disease are the most important predictors of improved diseasespecific survival in GCTs [3]. Thus, the patient was strongly recommended to undergo left adnexectomy. Histological examination after the second surgery confirmed residual GCT tissue in the left ovary, and the tumor was diagnosed as GCT stage Ic [4]. Stage Ia GCT disease has an excellent prognosis after surgery and does not require adjuvant therapy [5]. Some authors suggest adjuvant therapy for stage Ic patients with a high mitotic index [3]. Thus platinum-based chemotherapy was applied in this case. Furthermore, reexamination of the pituitary gland by MRI after surgery revealed a $5.7 \times 6.0$ $\mathrm{cm}$ tumor that did not differ in size from previous measurements. Neurosurgery consultation suggested that the pituitary adenoma was clinically nonfunctional and suggested yearly MRI for 2 years.

Spontaneous menstruation occurred soon after the surgery, and serum hormone levels decreased to normal levels, with LH of $9.03 \mathrm{IU} / \mathrm{L}$ and FSH of $8.54 \mathrm{IU} / \mathrm{L}$ on the second day of menstruation. The patient received three chemotherapy cycles of cisplatin, etoposide and bleomycin (PEB) as adjuvant treatment. Spontaneous menstruation returned twice during the peri-chemotherapeutic period: one day before and 50 days after chemotherapy. A recent hormonal profile revealed normal LH and FSH levels of 8.05 and $8.27 \mathrm{IU} / \mathrm{L}$. The fluctuations in the LH levels and sex hormone assays during treatment period are summarized in Table 1 and Fig. 2.

There have been several case reports of GCTs with secondary amenorrhea accompanied by alteration in various sex hormones [6-9]. Most of these cases were associated with low baseline FSH levels and high inhibin levels, but the serum levels of LH and estradiol were essentially normal in the majority of the patients. To the best of our knowledge, there have been only four cases

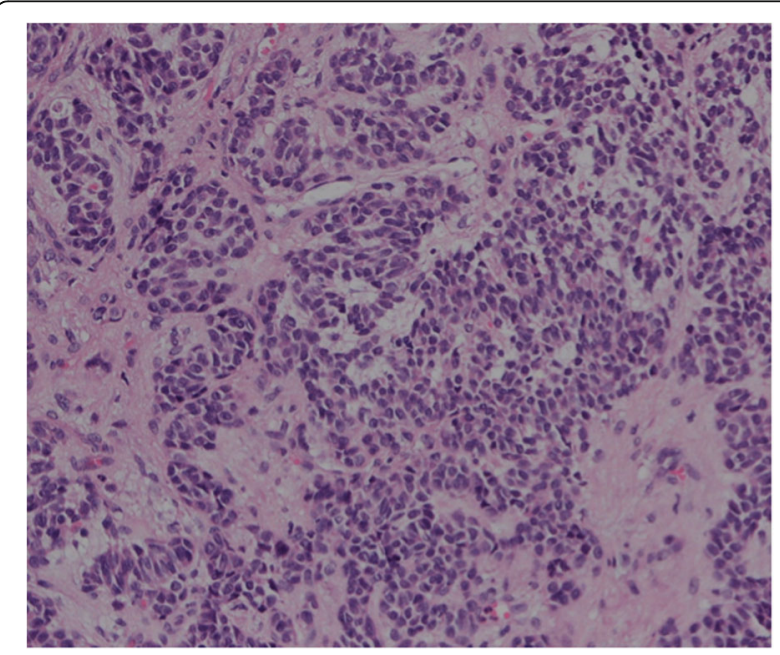

Fig. 1 Histological ovarian tumor findings. The tumor exhibited typical features of a granulosa cell tumor. H\&E, $\times 200$ 
reported $[8,10-12]$ thus far with a hormonal profile similar to our patient.

\section{Discussion and conclusions}

It was challenging to determine the etiology for the secondary amenorrhea and persistent markedly elevated $\mathrm{LH}$ with normal FSH and low E2 in this patient. The ovarian mass after 2 years of amenorrhea exhibited unremarkable growth by pelvic ultrasound. The initial assessment ruled out premature ovarian failure and polycystic ovary syndrome and led to the suspicion of a hypothalamicpituitary cause. However, pituitary microadenomas that secret LH are rare, and LH that was adequately suppressed using oral contraceptives led us to reject this diagnosis. Thus, surgical exploration of the ovary was performed and confirmed the diagnosis of GCT.

The reason for the elevation of LH levels in the present patient remains not clear. The gonadotropin profile prompted a review of some unusual etiologies of amenorrhea associated with high LH, normal FSH and low estradiol. Some hypotheses are suggested based on a literature review.

The production of LH by the ovarian tumor was ruled out by immunohistochemistry. The GCT may have secreted a factor that could stimulate LH secretion from the pituitary glands. One possible candidate factor is gonadotropin-releasing hormone $(\mathrm{GnRH})$-like substances, which have been detected in the normal granulosa cells of the ovary [13]. The GCT may have maintained GnRH production during tumorigenesis in this patient. Another possibility for the elevation of LH in GCTs is related to the $\mathrm{LH}$ receptor mutation, which is a rare cause of amenorrhea associated with LH elevation [6].

It was also worth noting that the ovarian mass had grown gradually during the 2 - year period $(2 \mathrm{~cm}$ to $3 \mathrm{~cm}$ ) under conditions of elevated $\mathrm{LH}$ and that $\mathrm{LH}$ decreased significantly after tumor removal. We wonder whether the relationship between the ovarian tumor and elevated LH levels may have been reciprocal. These two presentations may have influenced and affected by each other. On the one hand, the tumor may have secreted some substance that leads to the increased LH indirectly. Furthermore, elevated LH may have driven the growth of the tumor.

Low estradiol in this patient was unexpected because estradiol is typical one of the first markers identified in patients with GCTs. However, approximately 30\% of GCTs do not produce estradiol, perhaps related to the lack of theca cells, which produce androstenedione, a necessary precursor for estradiol synthesis.

Table 1 Serum sex hormone assays during the treatment period

\begin{tabular}{|c|c|c|c|c|c|c|c|}
\hline & & $\mathrm{LH} I U / \mathrm{L}$ & FSH IU/L & E2 pg/ml & $\mathrm{Tng} / \mathrm{ml}$ & $\mathrm{P}$ ng/ml & $\mathrm{PRL} \mathrm{ng} / \mathrm{ml}$ \\
\hline & $2013 / 8 / 16$ & 30.12 & 7.49 & 18.2 & 0.56 & 0.64 & 7.12 \\
\hline \multirow{2}{*}{$\begin{array}{l}\text { The second day of menstruation after taking oral } \\
\text { contraceptives }\end{array}$} & 2013/9/24 & 8.51 & 2.3 & & & & \\
\hline & $2013 / 12 / 6$ & 15.01 & 2.59 & 143.43 & 0.51 & 3.94 & 5.6 \\
\hline The second day of spontaneous menstruation & $2014 / 3 / 1$ & 20.78 & 2.63 & 37.86 & 0.47 & 1.26 & 16.08 \\
\hline \multirow[t]{3}{*}{ Dydrogesterone for 3 months } & $2014 / 7 / 3$ & 47.85 & 8.76 & 28.17 & 0.59 & 0.42 & 6.78 \\
\hline & 2014/9/18 & 38.36 & 8.01 & 22.89 & 0.71 & 0.42 & 7.61 \\
\hline & 2014/11/6 & 38.59 & 3.31 & 11 & 0.7 & 1.3 & 10.88 \\
\hline \multirow[t]{3}{*}{ Artificial cycle } & $2015 / 4 / 2$ & 34.53 & 5.28 & 34 & 0.48 & 0.41 & 5.58 \\
\hline & 2015/9/11 & 42.82 & 3.14 & 28 & 0.56 & 0.29 & 5.05 \\
\hline & $2016 / 1 / 25$ & 36.51 & 2.32 & 19.07 & 0.68 & 0.64 & 5.56 \\
\hline $\begin{array}{l}\text { The second day of menstruation after taking oral } \\
\text { contraceptives }\end{array}$ & $2016 / 4 / 5$ & 7.51 & 0.87 & $<5$ & 0.21 & 0.64 & 9.02 \\
\hline Two days before the first surgery & $2016 / 5 / 4$ & 26.14 & 2.54 & 19 & 0.61 & 0.71 & 7.18 \\
\hline Three days after the first surgery & 2016/5/9 & 24.99 & 6.48 & 26.09 & 0.15 & 0.91 & 27.28 \\
\hline Two weeks after the first surgery & $2016 / 5 / 20$ & 13.65 & 4.91 & 64 & 0.38 & 0.38 & 6.44 \\
\hline $\begin{array}{l}\text { Two days after the second surgery (menstruation } \\
\text { occurred after the surgery) }\end{array}$ & $2016 / 6 / 6$ & 9.03 & 8.54 & 30.23 & $<0.1$ & 0.69 & 10.77 \\
\hline Two days before the chemotherapy & $2016 / 6 / 28$ & 6.87 & 4.84 & 138 & 0.24 & 11.53 & 11.95 \\
\hline Chemotherapy & 2016/7/15 & 35.69 & 58.24 & 23 & 0.2 & 0.98 & \\
\hline Chemotherapy & $2016 / 8 / 5$ & 32.65 & 52.34 & 47 & $<0.1$ & 0.73 & 8.01 \\
\hline Fifty days after the chemotherapy & 2016/10/10 & 8.05 & 8.27 & & & & \\
\hline
\end{tabular}




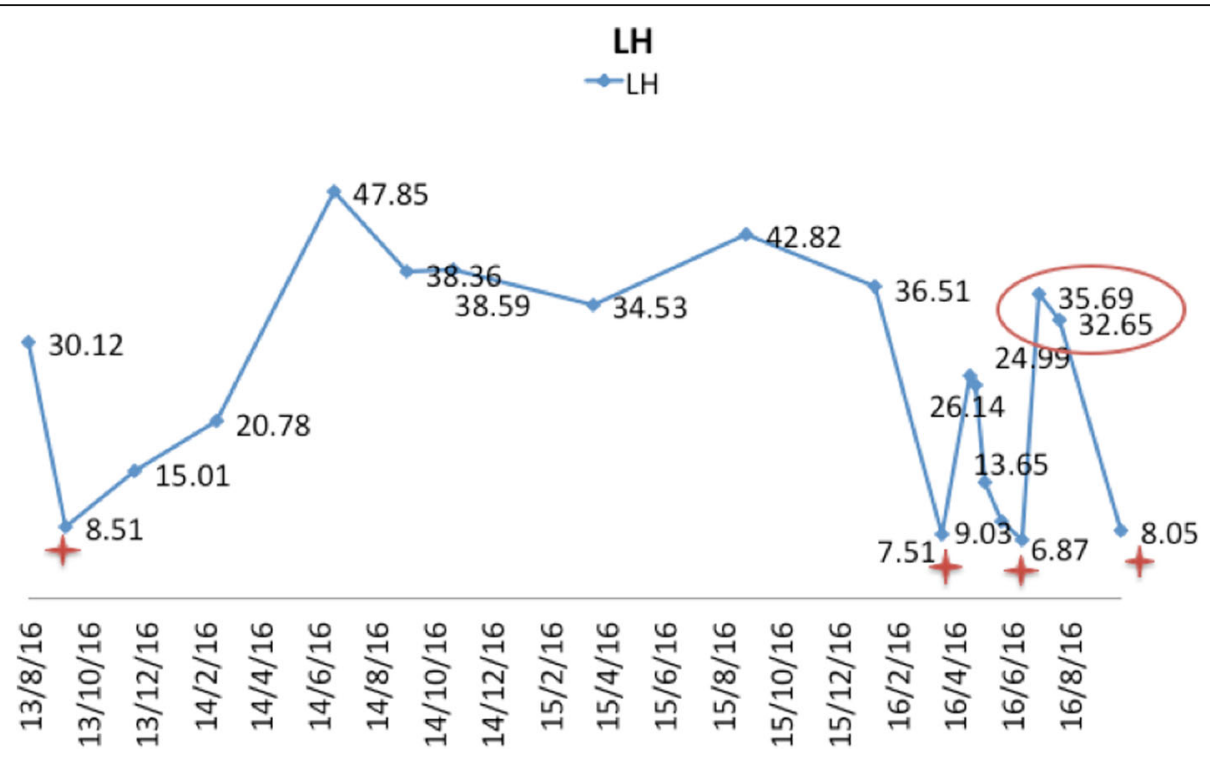

Fig. 2 LH level fluctuation during the treatment period. " LH levels exhibited 4 episodes of normalization during the entire treatment course: 2 involving oral contraceptive withdraw bleeding before the surgery, 1 after the left salpingo-oophorectomy and 1 after chemotherapy. LH levels during the chemotherapy period

Many of our hypotheses are unable to be tested because of ethical or technical restrictions. However, the case we present may provide some clinical basis to doctors who encounter similar cases. Further studies analyzing findings in GCTs associated with elevated serum LH may be helpful to elucidate the mechanisms of LH secretion regulated by the hypothalamus-pituitary-ovary axis.

Although GCTs can typically be diagnosed in the early stages in most patients secondary to the typical hormonal changes, the chance of recurrence remains high. Childbirth should be encouraged for infertile patients following the decline in the LH level and the recovery of normal ovulation after conservative surgery. Most cases in the literature succeeded in achieving natural pregnancy after tumor removal. For patients who failed to achieve natural pregnancy, conception guidance should be recommended.

In addition, monitoring serum $\mathrm{LH}$ is necessary and may provide additional tumor markers for such cases after conservative surgery. Patients should also pay attention to the regularity of their cycles, which may be the easiest way to discover possible recurrence. If a patient has an ovarian mass accompanied by endocrine disorders (especially rich blood flow signals on ultrasonography), an operation may be the appropriate diagnostic method, even if the mass is less than $5 \mathrm{~cm}$.

The mechanisms underlying elevated serum LH levels in GCTs require further investigations. However, addressing the clinical problems with respect to the patient's needs remains the most important current treatment approach.
Abbreviations

FSH: Follicle stimulating hormone; GCT: Ovarian granulosa cell tumors; GnRH: Gonadotropin-releasing hormone; hCG: Human chorionic gonadotropin; IRB: Institutional Review Board; LH: Luteinizing hormone; MRI: Magnetic resonance imaging; PEB: Chemotherapy of cisplatin, etoposide and bleomycin

\section{Acknowledgements}

The authors thank the Department of Pathology at Peking Union Medical College Hospital for assistance with pathological diagnosis.

Funding

Not applicable.

\section{Availability of data and materials}

All data generated or analyzed during this study are included in this published article.

\section{Authors' contributions}

All authors analyzed and interpreted the patient data according to the histological examination and the literature review. RSY was a major contributor in writing the manuscript, and YQ was in charge of the final approval of the version to be published. DS performed the surgery, and XL served as the reproductive endocrinology doctor who was responsible for the patient's treatment throughout this process. All authors read and approved the final manuscript.

Competing interests

The authors declare that they have no competing interests.

Consent for publication

Informed written consent was provided by the patient.

Ethics approval and consent to participate

Approval was obtained from the Institutional Review Board (IRB) of Peking Union Medical College Hospital for publishing this case report.

\section{Publisher's Note}

Springer Nature remains neutral with regard to jurisdictional claims in published maps and institutional affiliations. 
Received: 1 March 2017 Accepted: 18 April 2017

\section{Published online: 24 April 2017}

\section{References}

1. Young RH. Sex cord-stromal tumors of the ovary and testis: their similarities and differences with consideration of selected problems. Mod Pathol. 2005;18 Suppl 2:S81.

2. Schumer ST, Cannistra SA. Granulosa cell tumour of the ovary. J Clin Oncol. 2003;21:1180-9

3. Colombo N, Peiretti M, Garbi A, ESMO Guidelines Working Group, et al. Non-epithelial ovarian cancer: ESMO Clinical Practice Guidelines for diagnosis, treatment and follow-up. Ann Oncol. 2012;23 Suppl 7:vii20-6.

4. Shepherd JH. Revised FIGO staging for gynaecological cancer. Brit J Obstet Gynaecol. 1989;96:889-2.

5. Colombo N, Parma G, Zanagnolo V, et al. Management of ovarian stromal cell tumors. J Clin Oncol. 2007;25:2944-51.

6. Donovan $\mathrm{LE}$, Brain $\mathrm{PH}$, Duggan MA. Isolated luteinizing hormone (LH) elevation in a woman with secondary amenorrhea: a clue to the diagnosis of an inhibin B-producing thecoma and insights into the influence of inhibin B on LH. Fertil Steril. 2010;94 Suppl 3:1097.e9-1097.e12.

7. Taylor HC, Velasco ME, Flores SG, et al. Amenorrhea and failure to virilize in a patient with a testosterone secreting granulosa cell tumor. Clin Endocrinol. 1982;17 Suppl 6:557-67.

8. Lappöhn RE, Burger HG, Bouma J, et al. Inhibin as a marker for granulosacell tumors. N Engl J Med. 1989;321:790-3.

9. Agha-Hosseini M, Aleyaseen A, Safdarian L, Kashani L. Secondary amenorrhea with low serum luteinizing hormone and follicle-stimulating hormone caused by an inhibin A- and inhibin B-producing granulosa cell tumor. Taiwan J Obstet Gynecol. 2009;48 Suppl 1:72-5.

10. Nasu K, Fukuda J, et al. Granulosa cell tumor associated with secondary amenorrhea and serum luteinizing hormone elevation. Int J Clin Oncol. 2007;12:228-30.

11. Datta M, Winter-Roach BA, Fitzgerald C. Secondary amenorrhoea associated with an isolated elevated serum leuteinising hormone: an unusual presentation of a granulosa cell tumour. J Obstet Gynaecol. 2006;26 Suppl 8:830-2.

12. Arteaga E, Campusano C, Fernández C. Secondary amenorrhea and LH hypersecretion. An unusual report of a granulosa cell ovarian tumor. Rev Med Chil. 1993;121 Suppl 4:420-4.

13. Cheung CK, Leung PCK. Molecular biology of gonadotropinreleasing hormone (GnRH)-I, GnRH-II, and their receptors in humans. Endocr Rev. 2005;26:283-306.

\section{Submit your next manuscript to BioMed Central and we will help you at every step:}

- We accept pre-submission inquiries

- Our selector tool helps you to find the most relevant journal

- We provide round the clock customer support

- Convenient online submission

- Thorough peer review

- Inclusion in PubMed and all major indexing services

- Maximum visibility for your research

Submit your manuscript at www.biomedcentral.com/submit

) Biomed Central 